\title{
Comparison of Fusion Rate between Demineralized Bone Matrix versus Autograft in Lumbar Fusion : Meta-Analysis
}

\author{
Sanghyun Han, ${ }^{1}$ Bumsoo Park, Jeong-Wook Lim, ${ }^{1}$ Jin-Young Youm, ${ }^{1}$ Seoung-Won Choi, ${ }^{1}$ Dae Hwan Kim, ${ }^{2}$ Dong Ki Ahn ${ }^{3}$ \\ Department of Neurosurgery, Chungnam National University Hospital, Chungnam National University College of Medicine, Daejeon, Korea \\ Department of Neurosurgery, ${ }^{2}$ Yonsei University College of Medicine, Seoul, Korea \\ Department of Orthopedic Surgery, ${ }^{3}$ Seoul Sacred Heart General Hospital, Seoul, Korea
}

The demineralized bone matrix (DBM) as the bone graft material to increase the fusion rate was widely used in spinal fusion. The current study aimed to compare the fusion rate of DBM to the fusion rate of autograft in lumbar spine fusion via meta-analysis of published literature. After systematic search, comparative studies were selected according to eligibility criteria. Checklist (risk of bias assessment tool for non-randomized study) was used to evaluate the risk of bias of the included nonrandomized controlled studies. The corresponding $95 \%$ confidence interval $(95 \% \mathrm{Cl})$ were calculated. We also used subgroup analysis to analyze the fusion rate of posterolateral lumbar fusion and lumbar interbody fusion. Eight studies were finally included in this meta-analysis. These eight studies included 581 patients. Among them, 337 patients underwent spinal fusion surgery using DBM (DBM group) and 204 patients underwent spinal fusion surgery with mainly autologous bone and without using DBM (control group). There was no significant differences of fusion rate between the two groups in posterolateral fusion analysis (risk ratio [RR], 1.03; 95\% Cl, 0.90-1.17; $p=0.66$ ) and interbody fusion analysis (RR, 1.13; $95 \% \mathrm{Cl}, 0.91-1.39 ; p=0.27)$. Based on the available evidence, the use of DBM with autograft in posterolateral lumbar spine fusion and lumbar interbody fusion showed a slightly higher fusion rate than that of autograft alone; however, there was no statistically different between two groups.

Key Words : Bone demineralization technique · Autografts · Lumbar vertebrae · Spinal fusion · Meta-analysis.

\section{INTRODUCTION}

Bone fusion is a very important process in spinal fusion surgery. Failure to achieve bone fusion after surgery leads to several complications. Pseudarthrosis, the result of failed spinal fusion, can cause implant migration or breakage and pedicle screw loosening. With further progression of pseudarthrosis, spinal instability can be initiated and the clinical outcome worsens ${ }^{16,33)}$.

To prevent pseudarthrosis in spinal fusion surgery, proper use of implant and preparation of bone fusion bed are two important aspects. However, the selection of good bone graft material is also a critical factor. Autologous iliac crest bone graft (ICBG) is the standard bone graft material in spinal fusion surgery ${ }^{10,11}$. However, the amount of autologous ICBG is limited, and there are several complications due to ICBG us-

- Received : October 4, 2019 •Revised : October 28, 2019 •Accepted : January 17, 2020

- Address for reprints : Seoung-Won Choi

Department of Neurosurgery, Chungnam National University Hospital, Chungnam National University College of Medicine, 282 Munhwa-ro, Jung-gu, Daejeon 35015, Korea Tel : +82-42-280-7361, Fax : +82-42-280-7364, E-mail : swchoi@cnu.ac.kr, ORCID : https://orcid.org/0000-0001-8610-887X

This is an Open Access article distributed under the terms of the Creative Commons Attribution Non-Commercial License (http://creativecommons.org/licenses/by-nc/4.0) which permits unrestricted non-commercial use, distribution, and reproduction in any medium, provided the original work is properly cited. 
age, such as hematoma, infection, and pain ${ }^{3,31)}$. Therefore, surgeons require an alternative bone graft material with osteoinductive and osteoconductive ability equivalent to that of $\mathrm{ICBG}^{15}$.

Demineralized bone matrix (DBM), prepared from allograft bone by demineralization techniques, theoretically has bone morphogenetic protein (BMP) and osteoinductive abili$\mathrm{ty}^{2}$. According to previous studies, the effect of DBM in spinal fusion surgery is still controversial ${ }^{6,32)}$. We therefore conducted this meta-analysis to further evaluate the fusion rate of group using DBM compared to that of another group using autograft bone in lumbar spinal fusion surgery.

\section{MATERIALS AND METHODS}

\section{Study selection}

To identify the relevant studies, we searched the following databases using controlled vocabulary and free-text words described in Supplementary Material : Pubmed (MEDLINE), EMBASE, the Cochrane Central Register of Controlled Trials (CENTRAL), the Web of Science, and SCOPUS. This study is based on the Cochrane Review Methods, and reporting was conducted according to the Preferred Reporting Items for Systematic Reviews and Meta-Analyses (PRISMA). We aimed to identify all relevant studies regardless of language, publication type (article, poster, conference article, etc.), journal and date. This search was updated in March 2019 and includes reference list of the studies and review articles identified. There were no restrictions on start dates for articles found.

\section{Eligibility criteria}

We selected studies based on the following criteria : 1) studies including patients who underwent lumbar spinal fusion surgery with screw fixation due to degenerative changes in the spine; 2) studies comparing bone fusion rates between group using autologous bone graft and another group using DBM in patients who underwent lumbar spinal fusion surgery; and 3) studies evaluating bone fusion rate using radiography and computed tomography (CT). Animal studies and non-comparative studies were excluded.

\section{Data collection}

Two reviewers independently recorded data from each study. Any disagreement between the two reviewers about data extraction was settled by the opinion of a third reviewer. The following data were extracted from the studies: study design, patient demographics, performed interventions, radiographic and clinical outcomes, statistical methods, and study results.

\section{Fusion evaluation}

The meta-analysis included only papers describing the fusion evaluation method. For radiographic evaluation of fusion, the evaluation should be carried out using previously published criteria or meet similar comparative criteria. Criteria included having the continuous bony bridging in CT scans or X-rays and/or minimal lack of movement in dynamic plain film.

\section{Assessment of methodological quality}

The risk of bias and the methodological quality were assessed as described in the Cochrane Handbook for Systematic Reviews of Interventions ${ }^{13)}$. The risk of bias for non-randomized experimental studies was assessed using the Risk of Bias Assessment Tool for Non-randomized Studies (RoBANS) for quality assessment. We evaluated the degree of effectiveness and quality of evidence for each outcome. Two investigators independently assessed the methodological quality of each study. Any disagreement between the two reviewers was resolved by consensus or by consultation with a third investigator. Publication bias was not assessed due to the small number of enrolled studies.

\section{Statistical analysis}

The meta-analysis was conducted using Review Manager (RevMan) version 5.2 (The Nordic Cochrane Centre, The Cochrane Collaboration, Copenhagen, Denmark). The randomeffects model was suitable for our study and was used to analyze fusion data. To evaluate fusion rate, we calculated the risk ratio (RR) in the included studies.

The heterogeneity among the studies was assessed using $\mathrm{I}^{2}$ statistic, with $\mathrm{I}^{2}$ values of $25 \%, 50 \%$, and $75 \%$ considered to be low, moderate, and high, respectively. Cochran's Q statistic (chi-square test) was also used to assess the heterogeneity, with a $p$ value $<0.10$ defining significant degree of heterogeneity. 


\section{RESULTS}

\section{Identification of studies}

Fig. 1 shows the details of study identification, inclusion, and exclusion criteria. An electronic search yielded 2291 studies in PubMed (MEDLINE), 2572 in EMBASE, 144 in the Cochrane Library, 3379 in the Web of Science, and 2596 in Scopus. After removing duplicates, 3606 studies remained, of which 3592 were excluded after reviewing the abstracts and full-text articles. Therefore, eight studies were finally included in this meta-analysis ${ }^{2,8,12,24,29,30,32,35)}$.

\section{Study characteristics and patient populations}

The meta-analysis included four prospective cohort studies, and four retrospective studies. There were six studies on posterolateral lumbar fusion surgery, two studies on lumbar interbody fusion, and one study on posterolateral lumbar fusion surgery and lumbar interbody fusion. These eight studies included 581 patients and 884 fusion levels. Among them, 377 patients underwent spinal fusion surgery using DBM (DBM group) and 204 patients underwent spinal fusion surgery with mainly autologous bone and without using DBM (control group). The details of the included studies are presented in Tables 1 and 2 .

\section{Quality of the included studies}

The results of quality assessment in eight studies included in this systematic review using RoBANS tool are summarized in Fig. 2. Overall, except for selection bias, these studies were rated as having low risk for other biases. Among the eight studies included in the assessment, 50\% were evaluated as having low risk in the selection of participants and confounding variables. The low risk ratios of the performance bias, the attrition bias, and the reporting biases were $87.5 \%$, respectively.

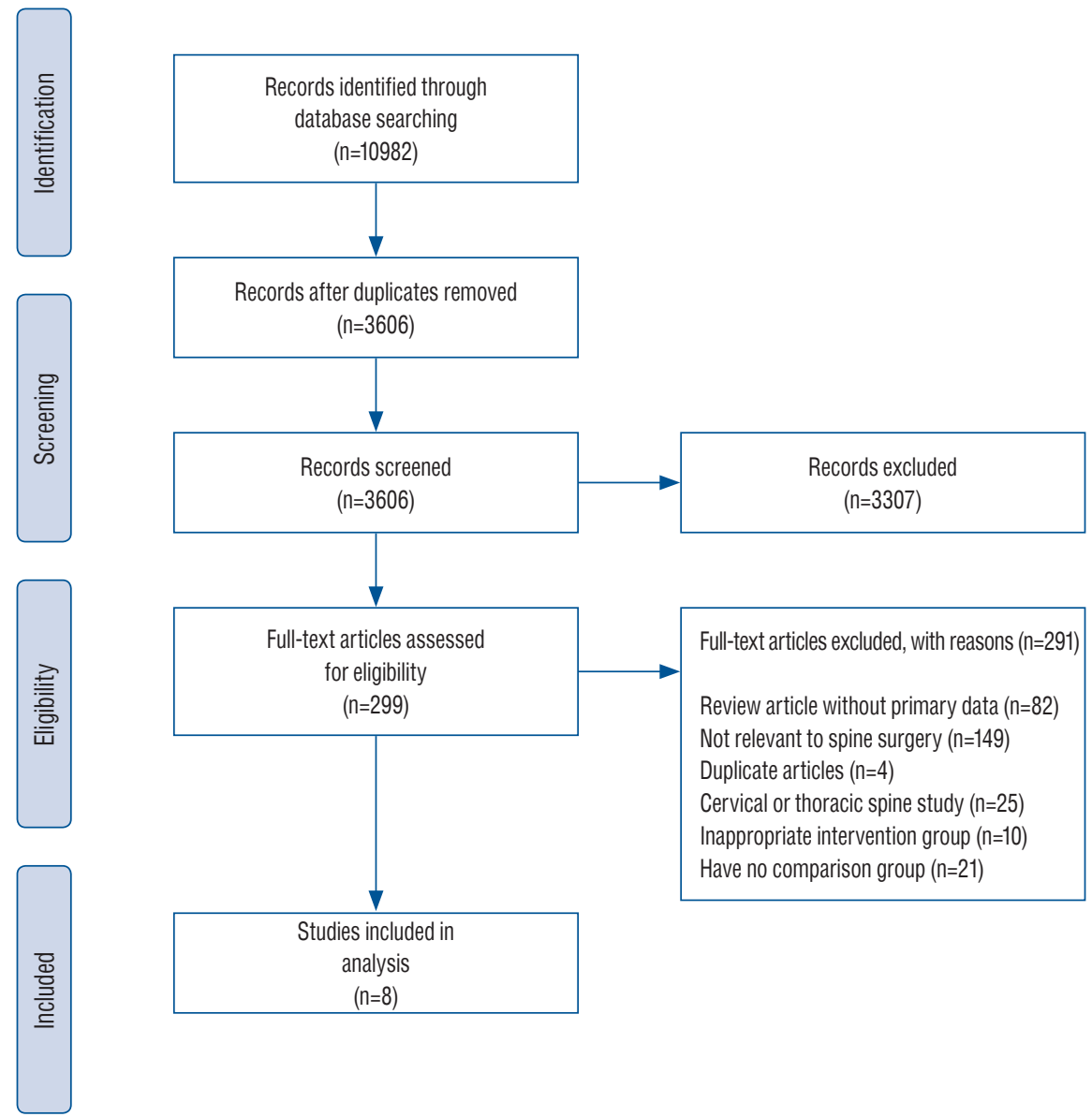

Fig. 1. Preferred Reporting Items for Systematic Reviews and Meta-Analyses flow diagram detailing the results of our meta-analysis of the medical literature. 


\section{The rate of posterolateral lumbar fusion}

Of the eight studies included in the meta-analysis, six described the rate of posterolateral lumbar fusion. Six studies included 377 patients who underwent posterolateral lumbar fu- sion surgery and described the fusion incidence in the DBM group and the control group as $71.7 \%(152 / 212)$ and $67.5 \%$ (114/169), respectively. However, there was no significant difference in the fusion rate between two groups (odds ratio

Table 1. Characteristics of the studies included in the meta-analysis

\begin{tabular}{|c|c|c|c|c|c|c|c|c|c|c|}
\hline \multirow[b]{2}{*}{ Study } & \multirow[b]{2}{*}{ Research type } & \multicolumn{2}{|c|}{ Number of patients } & \multirow{2}{*}{$\begin{array}{c}\text { Mean age, } \\
\text { DBM : control } \\
\text { group }\end{array}$} & \multirow{2}{*}{$\begin{array}{c}\text { Gender, } \\
M: F\end{array}$} & \multirow{2}{*}{$\begin{array}{l}\text { Fusion } \\
\text { method }\end{array}$} & \multirow{2}{*}{$\begin{array}{l}\text { Mean } \\
\text { follow } \\
\text { up }\end{array}$} & \multicolumn{2}{|c|}{ Fusion level } & \multirow{2}{*}{$\begin{array}{l}\text { Number } \\
\text { of level }\end{array}$} \\
\hline & & $\begin{array}{c}\text { DBM } \\
\text { group }\end{array}$ & $\begin{array}{l}\text { Control } \\
\text { group }\end{array}$ & & & & & 1 level & $\begin{array}{l}\text { Multilevel } \\
\text { ( } \geq 2 \text { levels) }\end{array}$ & \\
\hline $\begin{array}{l}\text { Sassard et al. }{ }^{29)} \\
(2000)\end{array}$ & Retrospective cohort & 52 & 56 & $40.4: 44.1$ & $71: 37$ & PLF & 24 & 40 & 68 & 191 \\
\hline $\begin{array}{l}\text { Thalgott et al. } \\
\text { (2001) }\end{array}$ & Retrospective cohort & 28 & 12 & $62^{*}$ & $14: 26$ & PLF & 70 & 11 & 29 & 77 \\
\hline $\begin{array}{l}\text { Vaccaro et al. }{ }^{35)} \\
(2007)\end{array}$ & Prospective cohort & 27 & 27 & $55.1: 55.7$ & $36: 37$ & $P L F+\mid B F$ & 24 & 44 & 29 & 104 \\
\hline $\begin{array}{l}\text { Schizas et al. }{ }^{30)} \\
(2008)\end{array}$ & Prospective cohort & 33 & 26 & $64.6: 58.3$ & $22: 37$ & PLF & 12 & 40 & 19 & 78 \\
\hline Fu et al. ${ }^{12)}$ (2016) & Retrospective cohort & 26 & 21 & $67.2: 65.1$ & $11: 36$ & PLF & 12 & 0 & 47 & 170 \\
\hline $\begin{array}{l}\text { Nam and } \mathrm{Yi}^{24)} \\
(2016)\end{array}$ & Retrospective cohort & 38 & 39 & $66.9: 67$ & $23: 54$ & PLF & 12 & 47 & 32 & 117 \\
\hline Choi et al. ${ }^{8)}(2008)$ & Prospective cohort & 15 & 12 & $65.3: 58.9$ & $9: 23$ & $\mathrm{IBF}$ & 6 & 22 & 17 & 46 \\
\hline Ahn et al. ${ }^{2)}$ (2014) & Prospective cohort & 59 & 38 & $63.7: 64.5$ & $18: 79$ & $\mathrm{IBF}$ & 34 & 71 & 14 & 99 \\
\hline
\end{tabular}

* Mean age of included patients. $M$ : male, F : female, PLF : posterolateral fusion, IBF : interbody fusion

Table 2. Perioperative data including operation time, length of hospital stay, graft material and fusion evaluation modality

\begin{tabular}{|c|c|c|c|c|c|c|c|c|c|c|}
\hline \multirow[t]{2}{*}{ Study } & \multicolumn{2}{|c|}{$\begin{array}{l}\text { Operation time } \\
\quad \text { (minutes) }\end{array}$} & \multicolumn{2}{|c|}{$\begin{array}{l}\text { Length of } \\
\text { hospital stay } \\
\text { (days) }\end{array}$} & \multicolumn{2}{|c|}{$\begin{array}{l}\text { Graft material in } \\
\text { interbody fusion }\end{array}$} & \multicolumn{2}{|c|}{$\begin{array}{l}\text { Graft material in posterolateral } \\
\text { fusion }\end{array}$} & \multirow{2}{*}{$\begin{array}{c}\text { Volume } \\
\text { of DBM } \\
\text { in DBM } \\
\text { group }\end{array}$} & \multirow{2}{*}{$\begin{array}{c}\begin{array}{c}\text { Fusion } \\
\text { evaluation } \\
\text { modality }\end{array} \\
\text { CT scans } \\
\text { or X-ray }\end{array}$} \\
\hline & $\begin{array}{c}\text { DBM } \\
\text { group }\end{array}$ & $\begin{array}{l}\text { Control } \\
\text { group }\end{array}$ & $\begin{array}{l}\text { DBM } \\
\text { group }\end{array}$ & $\begin{array}{l}\text { Control } \\
\text { group }\end{array}$ & $\begin{array}{l}\text { DBM } \\
\text { group }\end{array}$ & $\begin{array}{l}\text { Control } \\
\text { group }\end{array}$ & DBM group & Control group & & \\
\hline $\begin{array}{l}\text { Sassard et al. }{ }^{29)} \\
(2000)\end{array}$ & & & & & & & DBM+autobone & Autobone & $\begin{array}{l}\text { Not } \\
\text { mentioned }\end{array}$ & X-ray \\
\hline $\begin{array}{l}\text { Thalgott et al. } \\
\text { (2001) }\end{array}$ & & & & & & & $\mathrm{DBM}+$ autobone+HA & Autobone+HA & $\begin{array}{l}10 \mathrm{~mL} \text { per } \\
\text { level }\end{array}$ & X-ray \\
\hline $\begin{array}{l}\text { Vaccaro et al. } \\
\text { (2007) }\end{array}$ & 213.5 & 210 & 4.7 & 5.2 & $\begin{array}{c}\text { DBM+ } \\
\text { autobone }\end{array}$ & Autobone & DBM+autobone & Autobone & $\begin{array}{l}\text { Not } \\
\text { mentioned }\end{array}$ & X-ray \\
\hline $\begin{array}{l}\text { Schizas et al. }{ }^{30)} \\
(2008)\end{array}$ & 241 & 244 & & & & & DBM+autobone & Autobone & $2.5-10 \mathrm{~mL}$ & X-ray \\
\hline $\begin{array}{l}\text { Fu et al. } \\
\text { (2016) }\end{array}$ & 284.8 & 604.6 & 10.4 & 11.3 & & & $\mathrm{DBM}+$ autobone+HA & Autobone+HA & $5 \mathrm{~mL}$ & X-ray \\
\hline $\begin{array}{l}\text { Nam and } Y i^{24)} \\
\text { (2016) }\end{array}$ & & & & & & & DBM+autobone & Autobone & $\begin{array}{l}5 \mathrm{~mL} \text { per } \\
\text { level }\end{array}$ & X-ray \\
\hline $\begin{array}{l}\text { Choi et al. }{ }^{8)} \\
(2008)\end{array}$ & & & & & $\begin{array}{c}\text { DBM+ } \\
\text { autobone }\end{array}$ & Autobone & & & $\begin{array}{l}1 \mathrm{~mL} \text { per } \\
\text { level }\end{array}$ & CT scans \\
\hline $\begin{array}{l}\text { Ahn et al. }{ }^{2)} \\
(2014)\end{array}$ & & & & & $\begin{array}{c}\text { DBM+ } \\
\text { autobone }\end{array}$ & Autobone & & & $\begin{array}{l}1 \mathrm{~mL} \text { per } \\
\text { level }\end{array}$ & X-ray \\
\hline
\end{tabular}

DBM : demineralized bone matrix, CT : computed tomography, HA : hydroxyapatite 
[OR], 1.03; 95\% confidence interval [CI], 0.90-1.17; $p=0.66$ ). There was no heterogeneity among the selected studies evaluating the fusion rate $\left(\mathrm{I}^{2}=0 \%, p=0.48\right)$ (Fig. 3 ).

\section{The rate of lumbar interbody fusion}

Of the eight studies included in the meta-analysis, three described the rate of lumbar interbody fusion as 70.1\% (89/127) in the DBM group and $62.6 \%$ (48/77) in the control group, respectively. There was no significant difference in the fusion

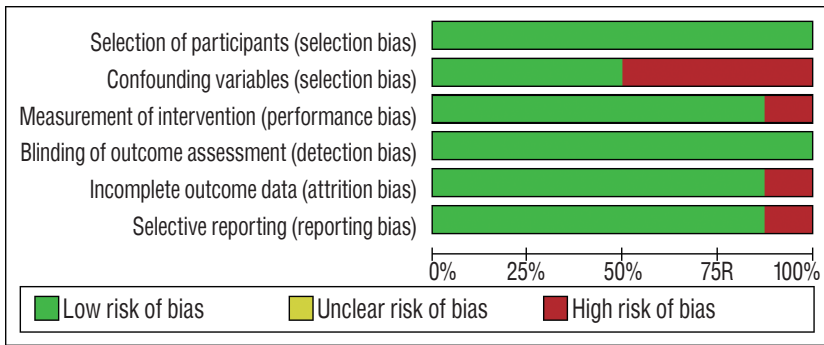

Fig. 2. Risk of bias graph : review authors' judgements about each risk of bias item presented as percentages across all included studies. rate between two groups (OR, 1.13; 95\% CI, 0.91-1.39; $p=0.27)$. There was a heterogeneity among the selected studies evaluating the fusion rate $\left(\mathrm{I}^{2}=57 \%, p=0.10\right)$ (Fig. 4).

\section{DISCUSSION}

Autologous ICBG has been rated as the gold standard graft material in spinal fusion surgery ${ }^{7,10)}$. However, it is known that there are several complications associated with the ICBG harvest $^{3,31)}$. Usage of recombinant BMP as the osteoinductive agent can achieve 94-99\% fusion rate in spinal fusion surgery, but it has complications like radiculitis, ectopic bone formation, seroma formation, etc. ${ }^{14,27)}$. To our knowledge, there are few reports about the complications due to usage of DBM as the bone graft in spinal fusion surgery.

Although DBM showed promising results in spinal fusion in animals, the results in humans were somewhat different ${ }^{19,21,23,26)}$. The study by Cammisa et al. ${ }^{6}$, which was a pos-

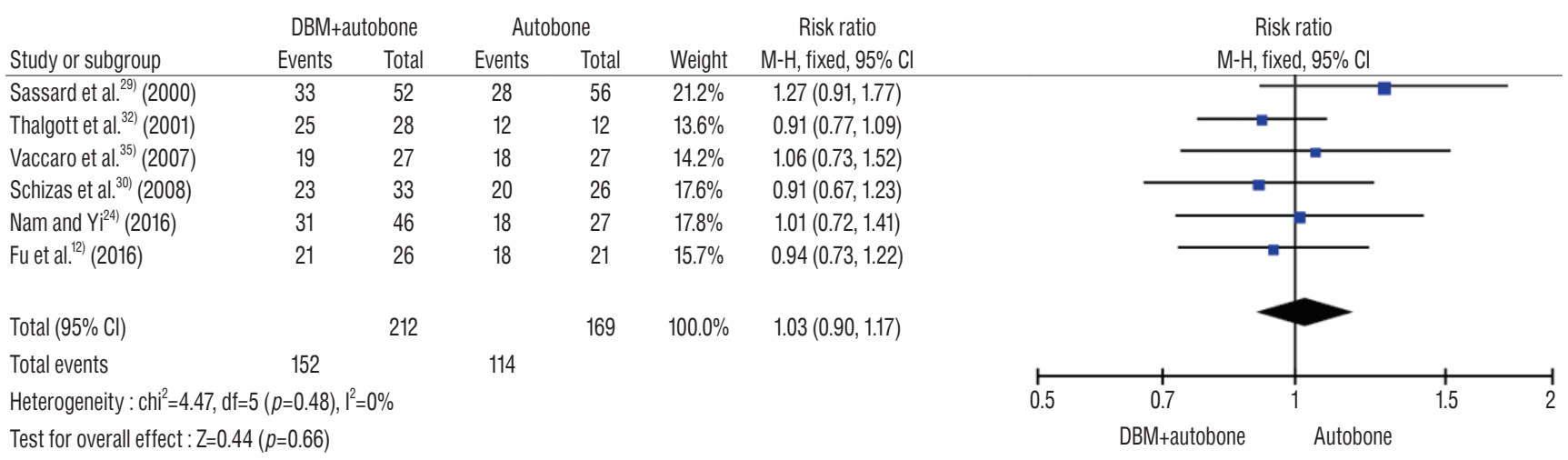

Fig. 3. Forest plots comparing fusion rate between DBM group and autobone group in lumbar posterolateral fusion surgery. $\mathrm{Cl}$ : confidence interval, $\mathrm{M}-\mathrm{H}$ : Mantel-Haenszel, DBM : demineralized bone matrix.

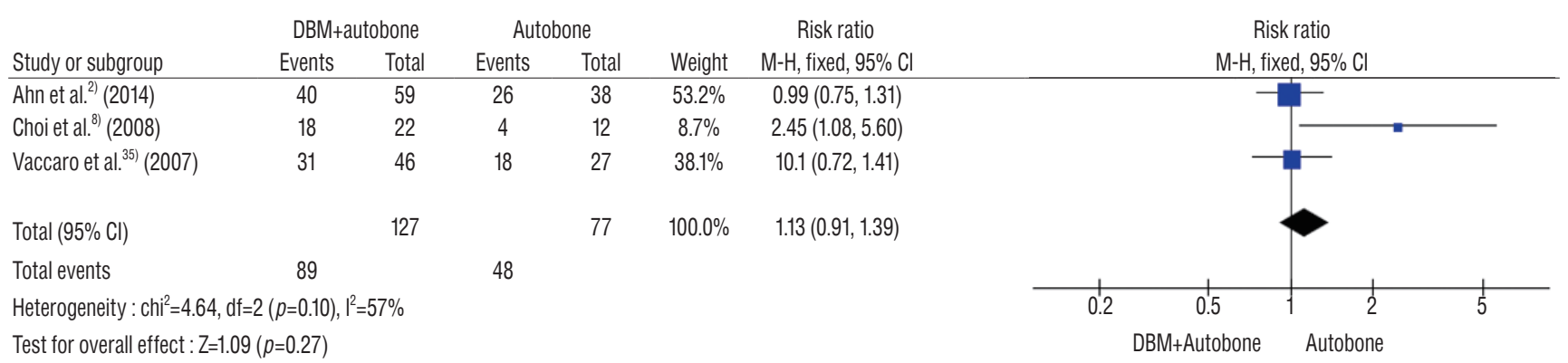

Fig. 4. Forest plots comparing fusion rate between DBM group and autobone group in lumbar interbody fusion surgery. $\mathrm{Cl}$ : confidence interval, $\mathrm{M}-\mathrm{H}$ : Mantel-Haenszel, DBM : demineralized bone matrix. 
terolateral lumbar fusion study in which DBM and autologous bone were inserted on one side and only autologous bone was inserted on the other side, reported that the fusion rate with DBM was similar to that with ICBG. Unlike this favorable result, Thalgott et al. ${ }^{32)}$ reported that the pseudarthrosis rate in the DBM group was higher than that in the DBM-less group. Overall, the efficacy of DBM in spinal fusion surgery is still controversial in view of the clinical results of $\mathrm{DBM}^{9,22,25,34)}$.

Therefore, we performed a meta-analysis to determine the effectiveness of DBM in spinal fusion surgery. First, in the observational studies of posterolateral lumbar fusion surgery, the overall fusion rate drops slightly in the DBM group compared to the control group. However, the fusion rate in the DBM group is not statistically different from that in the control group. Second, the results of lumbar interbody fusion surgery study were similar to those of the posterolateral lumbar fusion surgery study. These results may indicate that DBM is less effective as a graft enhancer than autologous bone. However, these studies suggest that DBM has an autologous bone -like graft extender capacity by showing a bone union rate similar to autologous bone.

This result was observed due to the characteristics of DBM. First, DBM is affected by the donor's age, sex, and other unique characteristics which determine the efficacy of $\mathrm{DBM}^{1)}$. Second, the manufacturing process of DBM differs from company to company. The intervariability and intravariability of BMP in each DBM product are detected by experimental procedures $^{4,5)}$. According to the study by Bae et al. ${ }^{5)}$, in each DBM product, concentration range of BMP-2 and BMP-7 are 20-120 ng/g and 54-226 ng/g, respectively. The quantity of $\mathrm{BMP}$ as the osteoinductive agent is too small in DBM product. Nevertheless, it is important to note that DBM has osteoinductive property. So, according to the result of this meta-analysis, DBM might have played role as a graft extender like autologous bone, rather than a graft enhancer.

\section{Limitation of the study}

This study has several limitations. Almost all the studies included in this meta-analysis are observational studies, suggesting inherent heterogeneity due to uncontrolled bias. Slight differences in different factors such as surgical skill, amount of graft material, sagittal balance, age, and density of bone, which could affect fusion rate may have increased the heterogeneity of the studies involved.
Some studies have included hydroxyapatite (HA) in the DBM group or autobone group. Particularly, since the components of HA do not contain BMP and their direct osteoinduction ability is substantially low, they are included in the study $^{17,18,28)}$.

The fusion rate of posterolateral fusion is a bit higher than its interbody fusion. As a result of something different from other studies ${ }^{20)}$, the reason is mean follow-up duration. Follow-up duration is a little longer in posterolateral fusion studies than interbody fusion studies. Moreover, there is a variation in the number of surgical levels and it may be the confounding factor for this analysis. Additionally, the volume of DBM is different in each study, and two studies don't describe the amount of DBM. Therefore, in terms of the volume of DBM, this meta-analysis study has heterogeneity and confounding factors.

Despite these limitations, this meta-analysis provides a snapshot of the best possible evidence currently available on the use of DBM in lumbar spinal fusion surgery.

Another limitation of this study is that there is no heterogeneity between studies of posterolateral fusion. This is only statistical point. Because the studies included in this study are observational studies, there is basically a heterogeneity between studies.

\section{CONCLUSION}

Based on the available evidence, the use of DBM with autograft in posterolateral lumbar spine fusion and lumbar interbody fusion showed a slightly higher fusion rate than that of autograft alone; however, there was no statistically different between two groups.

\section{CONFLICTS OF INTEREST}

No potential conflict of interest relevant to this article was reported.

\section{INFORMED CONSENT}

This type of study does not require informed consent. 


\section{AUTHOR CONTRIBUTIONS}

\author{
Conceptualization : $\mathrm{SH}$, SWC \\ Data curation : SH, DHK, DKA \\ Formal analysis : $\mathrm{SH}, \mathrm{BP}$ \\ Methodology : SH, JWL \\ Project administration : SH, SWC \\ Visualization : SH \\ Writing - original draft : $\mathrm{SH}$ \\ Writing - review \& editing : JYY, SWC
}

\section{ORCID}

Sanghyun Han https://orcid.org/0000-0003-3793-2904

Bumsoo Park https:/orcid.org/0000-0001-7828-4371

Jeong-Wook Lim https://orcid.org/0000-0003-1395-3145

Jin-Young Youm https://orcid.org/0000-0001-9609-0415

Seoung-Won Choi https://orcid.org/0000-0001-8610-887X

Dae Hwan Kim https://orcid.org/0000-0003-1594-1156

Dong Ki Ahn https://orcid.org/0000-0003-4075-3632

\section{- Acknowledgements}

This work was supported by research fund of Chungnam National University.

\section{- Supplementary materials}

The online-only data supplement is available with this article at https://doi.org/10.3340/jkns.2019.0185.

\section{References}

1. Aghdasi B, Montgomery SR, Daubs MD, Wang JC : A review of demineralized bone matrices for spinal fusion: the evidence for efficacy. Surgeon $11: 39-48,2013$

2. Ahn DK, Moon SH, Kim TW, Boo KH, Hong SW : Demineralized bone matrix, as a graft enhancer of auto-local bone in posterior lumbar interbody fusion. Asian Spine J 8 : 129-137, 2014

3. Arrington ED, Smith WJ, Chambers HG, Bucknell AL, Davino NA : Complications of iliac crest bone graft harvesting. Clin Orthop Relat Res 329 : 300-309, 1996

4. Bae H, Zhao L, Zhu D, Kanim LE, Wang JC, Delamarter RB : Variability across ten production lots of a single demineralized bone matrix product. J Bone Joint Surg Am 92 : 427-435, 2010
5. Bae HW, Zhao L, Kanim LE, Wong P, Delamarter RB, Dawson EG : Intervariability and intravariability of bone morphogenetic proteins in commercially available demineralized bone matrix products. Spine (Phila Pa 1976) 31 : 1299-1306; discussion 1307-1308, 2006

6. Cammisa FP Jr, Lowery G, Garfin SR, Geisler FH, Klara PM, McGuire RA, et al. : Two-year fusion rate equivalency between Grafton DBM gel and autograft in posterolateral spine fusion: a prospective controlled trial employing a side-by-side comparison in the same patient. Spine (Phila Pa 1976) 29 : 660-666, 2004

7. Chen WJ, Tsai TT, Chen LH, Niu CC, Lai PL, Fu TS, et al. : The fusion rate of calcium sulfate with local autograft bone compared with autologous iliac bone graft for instrumented short-segment spinal fusion. Spine (Phila Pa 1976) 30 : 2293-2297, 2005

8. Choi DJ, Ahn DK, Lee S, Park HS, Jeon YW, Yang SJ, et al. : The effect of demineralized bone matrix as a graft enhancer in posterior lumbar interbody fusion using cage and local bone chips. J Korean Soc Spine Surg 15 : 157-164, 2008

9. Fay LY, Chang CC, Chang HK, Tu TH, Tsai TY, Wu CL, et al. : A Hybrid dynamic stabilization and fusion system in multilevel lumbar spondylosis. Neurospine 15 : 231-241, 2018

10. Fischgrund JS, Mackay M, Herkowitz HN, Brower R, Montgomery DM, Kurz LT : 1997 Volvo Award winner in clinical studies. Degenerative lumbar spondylolisthesis with spinal stenosis: a prospective, randomized study comparing decompressive laminectomy and arthrodesis with and without spinal instrumentation. Spine (Phila Pa 1976) 22 : 28072812, 1997

11. France JC, Yaszemski MJ, Lauerman WC, Cain JE, Glover JM, Lawson KJ, et al. : A randomized prospective study of posterolateral lumbar fusion. Outcomes with and without pedicle screw instrumentation. Spine (Phila Pa 1976) 24 : 553-560, 1999

12. Fu TS, Wang IC, Lu ML, Hsieh MK, Chen LH, Chen WJ : The fusion rate of demineralized bone matrix compared with autogenous iliac bone graft for long multi-segment posterolateral spinal fusion Orthopedics and biomechanics. BMC Musculoskelet Disord 17 : 3, 2016

13. Higgins JP, Green $S:$ Cochrane handbook for systematic reviews for interventions, ed 4. West Sussex : John Wiley \& Sons Ltd, 2011

14. Kadam A, Millhouse PW, Kepler CK, Radcliff KE, Fehlings MG, Janssen $M E$, et al. : Bone substitutes and expanders in spine surgery: a review of their fusion efficacies. Int J Spine Surg $10: 33,2016$

15. Kang J, An H, Hilibrand A, Yoon ST, Kavanagh E, Boden S: Grafton and local bone have comparable outcomes to iliac crest bone in instrumented single-level lumbar fusions. Spine (Phila Pa 1976) 37 : 1083-1091, 2012

16. Kornblum MB, Fischgrund JS, Herkowitz HN, Abraham DA, Berkower $D L$, Ditkoff JS : Degenerative lumbar spondylolisthesis with spinal stenosis: a prospective long-term study comparing fusion and pseudarthrosis. Spine (Phila Pa 1976) 29 : 726-733; discussion 733-734, 2004

17. Lee JH : Development of osteoconductive and osteoinductive bone healing materials. Bone Abstracts 5 : SS4.3, 2016

18. Lin L, Chow KL, Leng $Y$ : Study of hydroxyapatite osteoinductivity with an osteogenic differentiation of mesenchymal stem cells. J Biomed 
Mater Res A 89 : 326-335, 2009

19. Louis-Ugbo J, Murakami H, Kim HS, Minamide A, Boden SD : Evidence of osteoinduction by Grafton demineralized bone matrix in nonhuman primate spinal fusion. Spine (Phila Pa 1976) 29 : 360-366; discussion Z1, 2004

20. Madan S, Boeree NR : Outcome of posterior lumbar interbody fusion versus posterolateral fusion for spondylolytic spondylolisthesis. Spine (Phila Pa 1976) 27 : 1536-1542, 2002

21. Martin GJ Jr, Boden SD, Titus L, Scarborough NL : New formulations of demineralized bone matrix as a more effective graft alternative in experimental posterolateral lumbar spine arthrodesis. Spine (Phila Pa 1976) 24 : 637-645, 1999

22. Mayo BC, Haws BE, Bohl DD, Louie PK, Hijji FY, Narain AS, et al. : Postoperative fever evaluation following lumbar fusion procedures. Neurospine 15 : 154-162, 2018

23. Morone MA, Boden SD : Experimental posterolateral lumbar spinal fusion with a demineralized bone matrix gel. Spine (Phila Pa 1976) 23 : 159-167, 1998

24. Nam WD, Yi J : Bone union rate following instrumented posterolateral lumbar fusion: comparison between demineralized bone matrix versus hydroxyapatite. Asian Spine J 10 : 1149-1156, 2016

25. Navarro SM, Frankel WC, Haeberle HS, Ramkumar PN : Fixed and variable relationship models to define the volume-value relationship in spinal fusion surgery: a macroeconomic analysis using evidence-based thresholds. Neurospine 15 : 249-260, 2018

26. Oikarinen $\mathrm{J}$ : Experimental spinal fusion with decalcified bone matrix and deep-frozen allogeneic bone in rabbits. Clin Orthop Relat Res (162) : 210-218, 1982

27. Parajón A, Alimi M, Navarro-Ramirez R, Christos P, Torres-Campa JM, Moriguchi $Y$, et al. : Minimally invasive transforaminal lumbar interbody fusion: meta-analysis of the fusion rates. What is the optimal graft material? Neurosurgery $81:$ 958-971, 2017

28. Rahaman MN, Xiao W, Liu Y, Bal BS : Osteoconductive and Osteoin- ductive Implants Composed of Hollow Hydroxyapatite Microspheres in Narayan R, Colombo P (eds) : Advances in Bioceramics and Porous Ceramics VII: A Collection of Papers Presented at the 38th International Conference on Advanced Ceramics and Composites January 27-31, 2014 Daytona Beach, Florida. Hoboken : John Wiley \& Sons, 2015, Vol 35, p65

29. Sassard WR, Eidman DK, Gray PM, Block JE, Russo R, Russell JL, et al. : Augmenting local bone with grafton demineralized bone matrix for posterolateral spine fusion: avoiding second site autologous bone harvest. Orthopedics 23 : 1059-1065; discussion 1064-1065, 2000

30. Schizas C, Triantafyllopoulos D, Kosmopoulos V, Tzinieris N, Stafylas K : Posterolateral lumbar spine fusion using a novel demineralized bone matrix: a controlled case pilot study. Arch Orthop Trauma Surg 128 : 621625,2008

31. St John TA, Vaccaro AR, Sah AP, Schaefer M, Berta SC, Albert T, et al. : Physical and monetary costs associated with autogenous bone graft harvesting. Am J Orthop (Belle Mead NJ) 32 : 18-23, 2003

32. Thalgott JS, Giuffre JM, Fritts K, Timlin M, Klezl Z : Instrumented posterolateral lumbar fusion using coralline hydroxyapatite with or without demineralized bone matrix, as an adjunct to autologous bone. Spine J $1:$ 131-137, 2001

33. Tsutsumimoto $T$, Shimogata $M$, Yoshimura $Y$, Misawa $H$ : Union versus nonunion after posterolateral lumbar fusion: a comparison of long-term surgical outcomes in patients with degenerative lumbar spondylolisthesis. Eur Spine J 17 : 1107-1112, 2008

34. Ungureanu G, Chitu A, lancu I, Kakucs C, Maior T, Florian IS : Gender differences in the self-assessment of quality of life and disability after spinal fusion for chronic low back pain at a neurosurgical center in Eastern Europe. Neurospine 15 : 261-268, 2018

35. Vaccaro AR, Stubbs HA, Block JE : Demineralized bone matrix composite grafting for posterolateral spinal fusion. Orthopedics 30 : 567-570, 2007 